\title{
Composição Químico-Bromatológica, Fracionamento de Carboidratos e Cinética da Degradação in vitro da Fibra de Três Variedades de Cana-de-Açúcar (Saccharum spp.) ${ }^{1}$
}

\author{
José Augusto Gomes Azevêdo², José Carlos Pereira ${ }^{3}$, Augusto César de Queiroz ${ }^{3}$, Pedro \\ Crescêncio Souza Carneiro4, Rogério de Paula Lana ${ }^{4}$, Márcio Henrique Pereira Barbosa ${ }^{5}$, \\ Alberto Magno Fernandes ${ }^{6}$, Francisco Palma Rennó ${ }^{7}$
}

\begin{abstract}
RESUMO - Os objetivos do trabalho foram quantificar a composição químico-bromatológica; determinar as frações de carboidratos; e estimar as variáveis de cinética de degradação dos carboidratos fibrosos (CF) e não-fibrosos (CNF) de três variedades de cana-de-açúcar divergentes nutricionalmente. As variedades utilizadas foram SP80-1842, SP79-1011 e RB845257. As variedades de ciclo de produção intermediário apresentaram maiores valores de FDN e FDA comparadas à variedade de ciclo precoce. As relações FDN/Pol (polarização do caldo) encontradas foram, respectivamente, 2,7; 2,8; e 2,3 para as variedades SP80-1842, RB845257 e SP79-1011. A variedade SP79-1011 apresentou menor fração $\mathrm{C}$ e maior fração $\mathrm{B}_{2}$ dos carboidratos (27,8 e 33,3\%). Houve diferenças, por meio da técnica gravimétrica, para o tempo de colonização e a degradabilidade efetiva da FDN, com superioridade para a variedade SP79-1011, que apresentou valores respectivos de 7,9 h e 10,3\%. Houve efeito apenas para o volume máximo de gás dos CNF, com superioridade das variedades de ciclo intermediário SP79-1011 e RB845257. A variedade SP79-1011 foi a que apresentou melhores características produtivas, composição químico-bromatológica, além de melhores valores das variáveis de cinética de degradação dos carboidratos fibrosos (CF) e não-fibrosos (CNF). A técnica de produção de gás apresentou melhores resultados que aqueles apresentados pela técnica gravimétrica.
\end{abstract}

Palavras-chave: cana-de-açúcar, carboidratos, cinética, composição químico-bromatológica

\section{Chemical-Bromatological Composition, Fractionation of Carbohydrates and in vitro Fiber Degradation Kinetics of Three Sugarcane (Saccharum spp.) Varieties}

\begin{abstract}
The objectives of this work were to determine the chemical-bromatological composition, to determine the carbohydrates fractions and to estimate the kinetic variables of degradation of the fibrous (FC) and no-fiber carbohydrates (NFC), of three nutritional divergence sugarcane varieties. The studied varieties were SP80-1842, SP79-1011 and RB845257. The varieties of intermediary production cycle showed greater values of NDF and ADF compared to the variety of early cycle. The observed FDN/Pol (sucrose index) ratio was, respectively, 2.73; 2.82 and 2.25 for the SP80-1842, RB845257 and SP79-1011 varieties. The SP79-1011 variety presented smaller $\mathrm{C}$ and greater $\mathrm{B}_{2}$ carbohydrate fractions (27.78 and 33.26\%). It was possible to observe difference, using the gravimetric technique, for the lag time and the effective degradation of NDF, with higher values for SP 791011 variety (7.90 h and $10.30 \%$, respectively). However, for the gas production technique, there was only a significant effect, for the estimate of the maximum gas volume parameter for NFC, with higher values for the varieties SP79-1011 and RB845257 of intermediary production cycle. The SP79-1011 variety was the one that showed better productive characteristic, composition chemical-bromatological, besides better values of the kinetics variables of degradation of the fiber (FC) and non fiber (CNF) carbohydrates. The gas production technique was more reliable than the results observed by the gravimetric technique.
\end{abstract}

Key Words: carbohydrates, chemical-bromatological composition, kinetics, sugarcane

\section{Introdução}

Durante muito tempo, os critérios adotados para indicar uma variedade de cana-de-açúcar como forrageira não levava em consideração o valor nutritivo da variedade e baseava-se apenas em características agronômicas, como produção de massa verde, rusticidade, resistência a doenças, capacidade de perfilhamento, ausência de joçal e vigor de rebrota (Peixoto, 1968).

A qualidade de uma forrageira depende de seus constituintes, os quais variam, dentro de uma mesma espécie, de acordo com a idade e parte da planta,

\footnotetext{
${ }^{1}$ Parte da Dissertação de Mestrado em Zootecnia, apresentada pelo primeiro autor à Universidade Federal de Viçosa (UFV).

2 Professor do Departamento de Ciências Agrárias e Ambientais - Universidade Estadual de Santa Cruz (UESC). E.mail: augustog@uesc.br

${ }^{3}$ Professor do Departamento de Zootecnia - UFV, Bolsista do CNPq. E.mail: jcarlos@mail.ufv.br

${ }^{4}$ Professor do Departamento de Biologia Geral - UFV. E.mail: carneiro@mail.ufv.br

${ }^{5}$ Professor do Departamento Fitotecnia - UFV. E.mail: barbosa@ufv.br

${ }^{6}$ Zootecnista, DS. Professor da UENF. E.mail: alberto@uenf.br

${ }^{7}$ Doutorando em Zootecnia, DZO/UFV. E.mail: fprenno@alunos.ufv.br
} 
fertilidade do solo, entre outros (Van Soest, 1994). Entre os fatores que afetam a qualidade da cana-deaçúcar como alimento para bovinos, os mais importantes são idade da planta e a variedade (Rodrigues \& Esteves, 1992). O efeito da idade da planta está bem estabelecido (Lovadini, 1971; Alvarez \& Preston, 1976; Banda \& Valdez, 1976), no entanto, o efeito de variedade é pouco estudado, considerando-se o desempenho por bovinos.

Rodrigues et al. (2001), avaliando 18 variedades de cana-de-açúcar, verificaram diferenças de 12,3 unidades percentuais entre o menor teor de FDN (44,1\%), encontrado na variedade IAC 86-2480, e o maior valor de FDN (56,4\%), obtido para a variedade IAC 84-1042. Os constituintes da fibra das forrageiras tropicais são considerados de grande importância, por duas razões principais: 1) compreendem a maior fração da matéria seca da planta; 2) constituem a fração da planta menos digerida no trato digestivo e a mais lentamente digerida em nível de rúmen (Thiago \& Gill, 1993).

Sniffen et al. (1992) sugerem que os alimentos utilizados para os ruminantes sejam fracionados para formular dietas que promovam adequada digestão ruminal de carboidratos e proteínas e obter o máximo desempenho dos microrganismos ruminais, pois estariam minimizando as perdas energéticas e nitrogenadas no rúmen. Atualmente, só existem dois trabalhos de cana-de-açúcar sobre fracionamento de carboidratos dos autores Cabral et al. (2000) e Pereira et al. (2000), nos quais não foram citadas as variedades utilizadas, sendo estes divergentes em 19,8 pontos percentuais nos valores da fração $B_{2}$, a qual seria a fração potencialmente degradável dos carboidratos.

Qualquer consideração sobre a utilização de forragens pelos ruminantes deve basear-se no contexto das complexas interações que ocorrem entre os diversos componentes da planta e os microrganismos ruminais. Nesse aspecto, segundo Orskov (1986), a qualidade da forragem pode, essencialmente, ser expressa em termos de três características próprias: 1) a extensão da digestão potencial (determina a quantidade de material indigestível, o qual ocupa espaço no rúmen); 2) a taxa de fermentação (influencia o tempo em que a fração digestível ocupa espaço no rúmen); e 3) a taxa de redução do tamanho de partícula (influencia ambos, a taxa de passagem da fração indigestível e a taxa de fermentação da fração digestível, entretanto, o seu nível de influência é pouco conhecido, devido às dificuldades em mensurá-lo).
Van Soest (1994) observou que o consumo e a eficiência de utilização de energia, de determinado alimento, variam entre os animais, sendo, portanto, mais fácil o estabelecimento de valores alimentares para a digestibilidade, ou seja, a digestibilidade tem sido utilizada como variável de qualidade, indicando a proporção do alimento que está apta a ser utilizada pelo animal.

As técnicas de avaliação das variáveis da cinética da degradação ruminal dos alimentos compreendem estudos sobre o desaparecimento da massa de amostra incubada ao longo do tempo de incubação, denominada técnica gravimétrica, ou a quantificação da produção cumulativa de gases $\mathrm{CO}_{2}$ e $\mathrm{CH}_{4}$, oriunda da atividade microbiana ruminal a partir da fermentação de uma amostra em líquido ruminal tamponado, durante o período de incubação, conhecida como técnica metabólica (Menke et al., 1979; Pell \& Schofield, 1993; Theodorou et al., 1994).

Os modelos dinâmicos da digestão fornecem uma estimativa dos valores nutritivos para os alimentos, com a mudança da ração, da população microbiana e do estado fisiológico do animal, e também fornecem informações dos fatores que reprimem os processos digestivos (Mertens, 1993). Com a estimativa das variáveis da cinética dos nutrientes no trato gastrintestinal, é possível o fornecimento de rações mais adequadas, visando a máxima eficiência de síntese de proteína microbiana, bem como a redução das perdas energéticas e nitrogenadas decorrentes da fermentação ruminal, observando entre os alimentos a sincronização na degradação de nitrogênio e carboidratos no rúmen. Os trabalhos encontrados na literatura sobre degradabilidade efetiva da FDN da cana-de-açúcar (Santos, 1994; Franzolin \& Franzolin, 2000) não levam em consideração o período de latência nos modelos adotados.

A FDN dos alimentos apresentam um período de latência, em que não se verifica a degradação do substrato. Durante esse período, podem ocorrer hidratação das partículas do alimento, remoção de substâncias inibidoras, eventos ligados à adesão e efetiva colonização das partículas do alimento pelos microrganismos ruminais, de modo que, antes do término desta fase, o alimento permanece inalterado no rúmen, a não ser por ação mecânica. Desse modo, é justificável a utilização de modelos que determinam a contribuição do período de latência sobre a cinética de degradação ruminal (Mertens, 1977; McDonald, 1981; Pereira, 1992). 
A avaliação dos componentes químicobromatológicos, do fracionamento dos carboidratos e das variáveis da cinética de degradação dos carboidratos fibrosos (CF) e dos carboidratos não fibrosos (CNF) das variedades de cana-de-açúcar permitiria separar as frações que fossem completamente indegradáveis ou aquelas que reduzem a disponibilidade de energia para os microrganismos e estariam negativamente correlacionadas com a ingestão de matéria seca (Mertens, 1992), devido ao seu efeito sobre a repleção ruminal; conseqüentemente, interferem na eficiência de síntese de proteína microbiana e seu suprimento para o intestino delgado, reduzindo, assim, o desempenho animal.

Os objetivos deste trabalho foram quantificar a composição químico-bromatológica, determinar as frações de carboidratos e estimar as variáveis da cinética de degradação dos CF e CNF, de três variedades de cana-de-açúcar divergente nutricionalmente.

\section{Material e Métodos}

O experimento foi instalado em solo caracterizado como Podzólico Vermelho-Amarelo e efetuou-se o plantio em parcelas de cinco sulcos de 10 metros de comprimento cada, espaçamento de $1,10 \mathrm{~m}$ entre sulcos, densidade de gemas de 18 gemas por metro linear, topografia de meia encosta. Realizou-se somente adubação de plantio, de acordo com as recomendações da análise de solo, aplicando-se, por hectare, $400 \mathrm{~kg}$ de 06.30.24 de NPK.

O campo experimental localizava no Município de Oratório - MG, com altitude média de 422 m, definido pelas coordenadas geográficas de $20^{\circ} 40^{\prime}$ de latitude sul e $42^{\circ} 90$ ' de longitude Oeste, tendo clima, segundo a classificação de Köppen, do tipo Cwa (Coelho \& Ribeiro, 1988). Os dados climáticos foram fornecidos pelo boletim meteorológico do Posto do Centro de Pesquisa e Melhoramento da Cana-de-Açúcar (CECA) vinculado ao Departamento de Fitotecnia da Universidade Federal de Viçosa, localizado no município de Ponte Nova e encontram-se na Tabela 1.

As variedades de cana-de-açúcar utilizadas neste estudo foram: SP80-1842, SP79-1011 e RB845257, as quais foram previamente selecionadas por análise multivariada, via componentes principais, para diversidade nutricional relacionada à fração fibrosa da cana-de-açúcar. Elas foram selecionadas a partir das variáveis: fração indegradável da fibra em detergente neutro em incubação in situ, taxa de degradação da
FDN em incubação in situ, fibra em detergente neutro (FDN), hemicelulose e lignina.

As informações do ciclo de produção, da produção por tonelada da matéria natural, dos teores aparentes de sólidos solúveis no caldo (Brix \%) e da polarização do caldo (Pol \%) da cana foram fornecidas pelo laboratório de análises tecnológicas da Usina de Jatiboca, localizada no município de Oratório - MG.

Para determinação dos valores de nutrientes digestíveis totais (NDT), procedeu-se aos cálculos de acordo com Weiss (1993), que consiste em:

$$
\begin{gathered}
\mathrm{NDT}=(\mathrm{DVPB} * \mathrm{~PB})+\left(\mathrm{EE}^{*} 2,25\right)+(0,98 \\
(100-\mathrm{FDNn}-\mathrm{PB}-\mathrm{MM}-\mathrm{EE}-1))+0,75 \\
*((\mathrm{FDNn}-\mathrm{Lig}) *(\mathrm{Lig} / \mathrm{FDNn}) 0,667))-7
\end{gathered}
$$

em que DVPB corresponde à digestibilidade verdadeira da proteína bruta, que é calculada usando a proteína insolúvel em detergente ácido (PIDA), por intermédio da equação DVPB = $\exp (-0,012 *$ PIDA $)$; $\mathrm{PB}$, a proteína bruta; EE, a extrato etéreo; FDNn, a fibra em detergente neutro corrigido para nitrogênio; MM, a matéria mineral; Lig, a lignina.

Foram realizadas as análises de matéria orgânica, matéria mineral, proteína bruta e extrato etéreo, seguindo os procedimentos padrões da AOAC (1990). As análises de FDN, FDN corrigida para cinzas e proteína, fibra em detergente ácido (FDA) e lignina (utilizando permanganato de potássio) foram determinadas conforme Van Soest et al. (1991). O fracionamento dos carboidratos totais, da proteína insolúvel em detergente neutro e da proteína insolúvel em detergente ácido foi realizado conforme descrito por Sniffen et al. (1992), porém, a fração C dos carboidratos foi obtida do resíduo da fração FDN após 144 horas de incubação in vitro.

Para estimar as variáveis da cinética de degradação dos carboidratos fibrosos e não-fibrosos, foram utilizadas duas técnicas: a gravimétrica e a de produção de gás in vitro, com inóculo retirado de bovino castrado alimentado com dieta contendo $70 \%$ de volumoso e $30 \%$ de concentrado.

$\mathrm{Na}$ técnica gravimétrica, foi utilizado o modelo exponencial decrescente, corrigido para o período de latência descrito por Waldo (1970):

$$
\mathrm{Y}=\mathrm{B}^{*} \exp \left(-\mathrm{C}^{*}(\mathrm{t}-\mathrm{L})\right)+\mathrm{I}
$$

em que $\mathrm{Y}$ representa a quantidade do alimento que permanece no frasco de vidro a um tempo t; a variável B, a fração insolúvel potencialmente degradável; I, a assíntota, que representa biologicamente a proporção do nutriente que não pode sofrer ação dos microrganismos ruminais; c, a taxa de 
Tabela 1 - Média dos dados climáticos, no período de março de 1997 a setembro de 1998, em Ponte Nova , Minas Gerais Table 1 - Means of the climatic data, from March 1997 to September1998, in Ponte Nova, Minas Gerais

\begin{tabular}{|c|c|c|c|c|c|c|c|c|}
\hline \multirow[t]{2}{*}{$\begin{array}{l}\text { Ano } \\
\text { Year }\end{array}$} & \multirow[t]{2}{*}{$\begin{array}{l}\text { Mês } \\
\text { Month }\end{array}$} & \multirow[t]{2}{*}{$\begin{array}{c}\text { Ocorrência } \\
\text { de chuva (dias) } \\
\text { Rain } \\
\text { occurrence (days) }\end{array}$} & \multirow[t]{2}{*}{$\begin{array}{l}\text { Chuva } \\
\text { (mm) } \\
\text { Rainfall } \\
\text { (mm) }\end{array}$} & \multicolumn{3}{|c|}{$\begin{array}{c}\text { Temperatura } \\
\left({ }^{\circ} \mathrm{C}\right) \\
\text { Temperature } \\
\left({ }^{\circ} \mathrm{C}\right)\end{array}$} & \multirow[t]{2}{*}{$\begin{array}{c}\text { Evaporação } \\
\text { (mm) } \\
\text { Evaporation } \\
(\mathrm{mm})\end{array}$} & \multirow[t]{2}{*}{$\begin{array}{c}\text { Umidade } \\
\text { relativa do ar } \\
\text { (\%) } \\
\text { Relative } \\
\text { humidity (\%) }\end{array}$} \\
\hline & & & & $\begin{array}{l}\text { Máxima } \\
\text { Maximum }\end{array}$ & $\begin{array}{l}\text { Mínima } \\
\text { Minimum }\end{array}$ & $\begin{array}{c}\text { Média } \\
\text { Average }\end{array}$ & & \\
\hline 1997 & Março & 10 & 108,7 & 28,2 & 18,1 & 23,2 & 3,7 & 69,1 \\
\hline 1997 & $\begin{array}{l}\text { March } \\
\text { Abril } \\
\text { April }\end{array}$ & 3 & 46,8 & 28,3 & 17,0 & 22,7 & 3,5 & 68,2 \\
\hline 1997 & $\begin{array}{l}\text { Maio } \\
\text { May }\end{array}$ & 3 & 20,1 & 25,7 & 13,3 & 19,5 & 3,1 & 65,2 \\
\hline 1997 & $\begin{array}{l}\text { Junho } \\
\text { June }\end{array}$ & 4 & 41,6 & 25,5 & 10,5 & 17,4 & 2,8 & 65,3 \\
\hline 1997 & $\begin{array}{l}\text { Julho } \\
\text { July }\end{array}$ & 0 & 0,0 & 26,3 & 9,5 & 17,9 & 3,3 & 61,3 \\
\hline 1997 & $\begin{array}{l}\text { Agosto } \\
\text { August }\end{array}$ & 1 & 6,0 & 27,3 & 9,7 & 18,5 & 4,2 & 53,5 \\
\hline 1997 & $\begin{array}{l}\text { Setembro } \\
\text { September }\end{array}$ & 6 & 74,1 & 27,4 & 16,6 & 22,0 & 4,3 & 63,0 \\
\hline 1997 & $\begin{array}{l}\text { Outubro } \\
\text { October }\end{array}$ & 10 & 147,2 & 28,5 & 18,6 & 23,5 & 4,5 & 68,0 \\
\hline 1997 & $\begin{array}{l}\text { Novembro } \\
\text { November }\end{array}$ & 13 & 176,2 & 30,4 & 20,3 & 25,4 & 5,6 & 69,9 \\
\hline 1997 & $\begin{array}{l}\text { Dezembro } \\
\text { December }\end{array}$ & 19 & 217,1 & 29,8 & 20,8 & 25,3 & 5,3 & 72,5 \\
\hline 1998 & $\begin{array}{l}\text { Janeiro } \\
\text { January }\end{array}$ & 16 & 226,8 & 30,2 & 21,0 & 25,6 & 5,3 & 71,5 \\
\hline 1998 & $\begin{array}{l}\text { Fevereiro } \\
\text { February }\end{array}$ & 10 & 176,4 & 30,9 & 20,7 & 25,8 & 4,9 & 69,6 \\
\hline 1998 & $\begin{array}{l}\text { Março } \\
\text { March }\end{array}$ & 4 & 55,2 & 31,1 & 20,4 & 25,7 & 4,9 & 66,3 \\
\hline 1998 & $\begin{array}{l}\text { Abril } \\
\text { April }\end{array}$ & 3 & 32,6 & 29,0 & 17,4 & 23,2 & 4,3 & 72,2 \\
\hline 1998 & $\begin{array}{l}\text { Maio } \\
\text { May }\end{array}$ & 5 & 86,9 & 25,4 & 13,4 & 19,4 & 3,5 & 72,7 \\
\hline 1998 & $\begin{array}{l}\text { Junho } \\
\text { June }\end{array}$ & 1 & 3,9 & 24,2 & 11,2 & 17,1 & 3,2 & 72,7 \\
\hline 1998 & $\begin{array}{l}\text { Julho } \\
\text { July }\end{array}$ & 0 & 0,0 & 25,5 & 10,3 & 17,9 & 3,8 & 72,7 \\
\hline 1998 & $\begin{array}{l}\text { Agosto } \\
\text { August }\end{array}$ & 5 & 50,2 & 27,3 & 13,7 & 20,5 & 4,4 & 72,7 \\
\hline 1998 & $\begin{array}{l}\text { Setembro } \\
\text { September }\end{array}$ & 1 & 18,6 & 29,1 & 15,6 & 22,3 & 5,0 & 57,2 \\
\hline
\end{tabular}

degradação da fração insolúvel potencialmente degradável (B), expressa em h-1; e t, a variável independente tempo (expresso em horas).

A degradabilidade efetiva da FDN (DEFDN) foi estimada pela equação (Mertens \& Loften, 1980):

$$
\text { DEFDN }=B^{*} c^{*} \exp \left(-k^{*} L\right) /(c+k)
$$

em que k eqüivale à taxa de passagem da digesta pelo rúmen, assumindo-se valor de $\mathrm{k}$ igual a $5 \mathrm{~h}^{-1}$.

As variáveis da cinética dos carboidratos fibrosos
(CF) e não-fibrosos (CNF) foram estimadas a partir da técnica de produção de gás in vitro. Foi utilizado o modelo bicompartimental (descrito abaixo), ajustado às curvas de produção cumulativa de gás (Schofield et al., 1994).

$$
\begin{gathered}
\mathrm{V}=\mathrm{Vf}_{1} /(1+\exp (2-4 * \mathrm{C} 1 *(\mathrm{~T}-\mathrm{L})))+\mathrm{Vf}_{2} / \\
(1+\exp (2-4 * \mathrm{C} 2 *(\mathrm{~T}-\mathrm{L})))
\end{gathered}
$$

em que: $\mathrm{Vf}_{1}$ equivale ao volume máximo de gás da fração dos CNF; C1, à taxa de degradação $\left(h^{-1}\right)$ 
desta mesma fração (CNF); $\mathrm{Vf}_{2}$, ao volume máximo de gás da fração dos $\mathrm{CF} ; \mathrm{C}_{2}$, à taxa de degradação $\left(\mathrm{h}^{-1}\right)$ dos CF; e T e L, aos tempos de incubação (horas) e à latência (horas), respectivamente.

As leituras de pressão, em volts, foram convertidas para $\mathrm{mL}$ de gás, por meio do fator 8,68 , conforme Pell \& Schofield (1993).

Após estimativa das variáveis da cinética de degradação dos carboidratos, foram construídas as curvas de degradação da MS e dos CF e CNF, em função do tempo de incubação, para os dados obtidos pelo método de produção de gás. Com o somatório do volume de gás para cada tempo de leitura, puderam ser construídas as curvas de produção cumulativa dos gases oriundos da MS, sendo a curva correspondente à fração solúvel em detergente neutro (CNF) obtida pela diferença entre o gás da MS e o dos CF para cada tempo de incubação.

Os dados obtidos sobre a degradabilidade e produção de gás dos CF, nos diferentes métodos e nos diferentes tempos de incubação, foram ajustados por regressão não-linear pelo método de Gauss-Newton, conforme os respectivos modelos já informados anteriormente, implantado no "software" Sistemas de Análises Estatística e Genéticas - SAEG (UFV, 2000). Foram feitas análise de variância e teste de média comparando-se as variáveis dentro de cada modelo e entre as variedades de cana-de-açúcar estudadas.

\section{Resultados e Discussão}

\section{Composição químico-bromatológica}

As características produtivas e a composição químico-bromatológica das variedades de cana-deaçúcar, envolvidas neste estudo, podem ser observadas na Tabela 2.

A variedade SP80-1842 apresenta ciclo de produção precoce, enquanto as variedades RB845257 e SP79-1011, ciclo intermediário. A caracterização do ciclo de produção para indústria é muito importante, pois irá determinar o início da colheita e até onde ela pode ser efetuada, estabelecendo, dessa forma, um período útil de industrialização (PUI), que ocorre quando a cana-de-açúcar atinge teores mínimos de açúcares suficientes para permitir a extração e transformação em produtos comerciais (Brieger, 1968). Este autor considera a cana-de-açúcar madura para início de safra, quando atinge os seguintes valores mínimos: Brix (sólidos solúveis) 18\% caldo e Pol (sacarose) \% caldo 15,3\% ou Pol \% cana 13, pureza $85,0 \%$ e açúcares redutores de $1 \%$ no máximo. Os resultados apresentados na Tabela 2 mostram que as variedades de cana-de-açúcar em estudo apresentaram condições adequadas para colheita.

Os valores médios referentes aos teores de proteína bruta (PB) e extrato etéreo (EE) apresentaram diferença $(\mathrm{P}<0,05)$ pelo teste Duncan, entretanto, os valores percentuais de MM, PB e EE nas três variedades de cana-de-açúcar são pouco expressivos para contribuir na formulação de rações à base deste volumoso. Lovadini (1971) observou que a escolha de variedades de cana-de-açúcar pelo maior teor de PB não seria indicada, pois, em seu trabalho, notou-se correlação positiva entre os teores de PB e fibra.

Apesar de existir diferença $(\mathrm{P}<0,05)$ na característica de carboidratos totais (CT), esta diferença foi relativamente pequena e só foi significativa devido ao baixo coeficiente de variação (CV), o que a torna pouco expressiva para influenciar a escolha de variedades de cana-de-açúcar.

Quanto à produtividade (t/ha), apesar de não existir diferenças $(\mathrm{P}>0,05)$ entre as variedades, pode-se observar com o avançar da idade maior produção em toneladas de MS/ha. Nesse sentido, chamou a atenção a variedade SP79-1011, com produção de MS (35,5 tMS/ha), superior em mais de $20 \%$ às produtividades das outras variedades. Esta superioridade parece não ter sofrido influência pela precipitação pluviométrica, já que esta variedade foi colhida 123 dias após a variedade SP80-1842 e durante este período choveu 91,8 mm em apenas 10 dias. A variedade RB845257, apesar de ter sido colhida 61 dias após a variedade SP80-1842, teve menor produtividade, o que pode ter sido provocado pela baixa precipitação pluviométrica $(41,6 \mathrm{~mm})$ em apenas cinco dias, durante este período.

A produtividade de uma variedade, em termos de seu uso como volumoso para alimentação de ruminantes, é uma característica de grande importância, pois, quando duas ou mais variedades possuem as demais características semelhantes, ela torna-se limitante (Carvalho, 1992). Todavia, a cana selecionada para alimentação de bovinos deve ter a capacidade de manutenção da produtividade ao longo dos anos.

Apesar de o Brix ser uma variável mais difundida na área zootécnica como indicativo do teor de açúcar da cana-de-açúcar, a Pol, segundo Golçalves (1987), é a variável mais específica para avaliar o teor de sacarose presente na cana-de-açúcar, porque o Brix 
Tabela 2 - Características produtivas e composição químico-bromatológica das variedades de cana-de-açúcar Table 2 - Production characteristics and chemical-bromatological composition of the sugarcane varieties

\begin{tabular}{|c|c|c|c|c|}
\hline \multirow[t]{2}{*}{$\begin{array}{l}\text { Característica } \\
\text { Characteristic }\end{array}$} & \multicolumn{3}{|c|}{$\begin{array}{l}\text { Variedade de cana-de-açúcar } \\
\text { Sugarcane variety }\end{array}$} & \multirow[t]{2}{*}{ CV(\%) } \\
\hline & SP80-1842 & RB845257 & SP79-1011 & \\
\hline $\begin{array}{l}\text { Ciclo de produção } \\
\text { Production cycle }\end{array}$ & $\begin{array}{l}\text { Precoce } \\
\text { Early }\end{array}$ & $\begin{array}{l}\text { Intermediário } \\
\text { Intermediary }\end{array}$ & $\begin{array}{l}\text { Intermediário } \\
\text { Intermediary }\end{array}$ & \\
\hline $\begin{array}{l}\text { Produtividade (t/ha) } \\
\text { Yield }(\mathrm{t} / \mathrm{h} a)\end{array}$ & 106,0 & 96,4 & 117,6 & 21,0 \\
\hline $\begin{array}{l}\text { Colheita (dias) } \\
\text { Harvest (days) }\end{array}$ & 426 & 487 & 549 & \\
\hline $\begin{array}{l}\text { Brix (\% caldo) } \\
\text { Sugar index }(\%)\end{array}$ & $18,1^{\mathrm{b}}$ & $18,2^{\mathrm{b}}$ & $23,2^{\mathrm{a}}$ & 4,9 \\
\hline $\begin{array}{l}\text { Pol (\% cana) } \\
\text { Sucrose index (\%) }\end{array}$ & $16,1^{\mathrm{b}}$ & $16,9^{\mathrm{b}}$ & $21,1^{a}$ & 7,3 \\
\hline $\begin{array}{l}\text { MS (\%) } \\
D M(\%)\end{array}$ & 27,4 & 30,2 & 30,2 & 5,1 \\
\hline $\begin{array}{l}\mathrm{PB}(\% \mathrm{MS}) \\
C P(\% D M)\end{array}$ & $2,8^{\mathrm{a}}$ & $2,4^{\mathrm{b}}$ & $2,4^{b}$ & 6,5 \\
\hline $\begin{array}{l}\mathrm{EE}(\% \mathrm{MS}) \\
\mathrm{EE}(\% \mathrm{DM})\end{array}$ & $0,7^{\mathrm{ab}}$ & $0,8^{\mathrm{a}}$ & $0,7^{b}$ & 6,6 \\
\hline $\begin{array}{l}\text { FDNcp(\%MS) } \\
\text { NDFap }(\% D M)\end{array}$ & 42,1 & 45,8 & 46,1 & 4,6 \\
\hline $\begin{array}{l}\text { FDN (\%MS) } \\
N D F(\% D M)\end{array}$ & 43,8 & 47,6 & 47,6 & 4,4 \\
\hline $\begin{array}{l}\text { FDA (\%MS) } \\
A D F(\% D M)\end{array}$ & 25,2 & 27,8 & 27,2 & 6,4 \\
\hline $\begin{array}{l}\text { CT (\%MS) } \\
\text { TC (\%DM) }\end{array}$ & $95,2^{\mathrm{b}}$ & $95,9^{\mathrm{a}}$ & $95,8^{a}$ & 0,2 \\
\hline $\begin{array}{l}\operatorname{Lig}(\% \mathrm{FDN}) \\
\operatorname{Lig}(\% N D F)\end{array}$ & $17,1^{\mathrm{a}}$ & $14,7^{\mathrm{ab}}$ & $12,2^{b}$ & 11,5 \\
\hline $\begin{array}{l}\text { Hem (\%MS) } \\
\text { Hem (\%DM) }\end{array}$ & 18,6 & 19,8 & 20,4 & 14,5 \\
\hline $\begin{array}{l}\text { PIDN (\%PB) } \\
\text { NDIP (\%CP) }\end{array}$ & 27,0 & 30,9 & 30,9 & 15,5 \\
\hline $\begin{array}{l}\text { PIDA (\%PB) } \\
\text { ADIP (\%CP) }\end{array}$ & 10,8 & 11,4 & 10,9 & 13,0 \\
\hline $\begin{array}{l}\text { NDT (\%) } \\
\text { TDN (\%) }\end{array}$ & 55,8 & 52,5 & 51,5 & 3,9 \\
\hline
\end{tabular}

FDNcp - fibra em detergente neutro livre de cinzas e proteína (NDFap - neutral detergent fiber, ash and protein free); CT - carboidratos totais (TC - total carbohydrates); PIDN - proteína insolúvel em detergente neutro (NDIP - neutral detergent insoluble protein); PIDA - proteína insolúvel em detergente ácido (ADIP - acid detergent insoluble protein); NDT - nutrientes digestíveis totais (TDN - total digestible nutrients).

Médias, na linha, seguidas por letras diferentes são diferentes pelo teste Duncan $(\mathrm{P}<0,05)($ Means, within a row, followed by different letters are different by Duncan test $(P<.05)$.

apresenta, além da sacarose (Pol), açúcares redutores e não açúcares. Nos resultados apresentados na Tabela 2, tanto para o Brix quanto para a Pol, houve diferença $(\mathrm{P}<0,05)$, com superioridade para a variedade SP791011. É possível verificar que, à medida que aumentou a idade da cana e o teor de matéria seca, houve tendência para aumento dos valores de Brix e da Pol. Brugnaro et al. (1988) afirmam que o teor de açúcar da cana cresce à medida que diminui a atividade vegetativa, atingindo um máximo e depois volta a cair.

Pode-se observar que as variedades estudadas foram selecionadas para a indústria, já que os valo- res observados da Pol de $21,1 \%$ cana para a variedade de maior média (SP79-1011) e de $16,1 \%$ cana para a variedade de menor média (SP80-1842) foram superiores aos apresentados por Rodrigues et al. (2001), avaliando 18 variedades de cana-deaçúcar, encontraram variação no teor da Pol de 13,7 a $15,8 \%$ cana.

Apesar de as três variedades apresentarem diversidade nutricional para as características relacionadas à fração fibrosa da cana-de-açúcar, os valores médios para FDN foram, respectivamente, de 43,8; 47,6; e $47,6 \%$ na base da MS para as variedades 
SP80-1842, RB845257 e SP79-1011, sendo inferiores aos valores médios encontrados por Valadares Filho et al. (2002), que verificaram em 39 observações valor médio de 55,9 \pm 8,2\% na base da MS. Estes valores mostram que, entre os volumosos mais utilizados na alimentação de vacas leiteiras, estas variedades apresentaram baixo teor de FDN, em comparação aos valores médios nacionais, respectivamente, de 55,46; 57,85; e 73,25\% (MS), encontrados na silagem de milho, silagem de sorgo e capimelefante (Valadares Filho et al., 2002).

Segundo Gooding (1982), a relação FDN/açúcares é uma variável importante na escolha de variedades de cana-de-açúcar para alimentação de bovinos. Esse autor comenta que a relação FDN/açúcar deve ser baixa, ou seja, baixo conteúdo de FDN e alto conteúdo de açúcar, porque a variedade que apresenta elevado teor de FDN limitará em determinado grau a ingestão de cana-de-açúcar e, conseqüentemente, o consumo de energia. Além disso, Rodrigues et al. (2001) observaram que, quanto menor a relação FDN/açúcares, maior será a digestibilidade in vitro da matéria seca.

Conforme Rodrigues et al. (2001), a relação FDN/Pol pode servir de indicador de variedades de cana-de-açúcar para alimentação de ruminantes. Este autor menciona o valor de 3,02 como referência para esta indicação, obtido pela avaliação de 18 variedades de cana-de-açúcar, cuja relação FDN/Pol variou de 2,9 a 4,1. Os valores para esta relação encontrados neste estudo foram, respectivamente, de 2,7; 2,8; e 2,3, para as variedades SP80-1842, RB845257 e SP79-1011. Novamente, a baixa relação FDN/Pol das variedades avaliadas indica que estas variedades são mais especializadas para a indústria que as avaliadas por Rodrigues et al. (2001).

Houve diferença $(\mathrm{P}<0,05)$ para os teores de lignina, com destaque para a variedade SP79-1011, por apresentar menor teor (12,2\%, FDN), porém não diferiu ( $\mathrm{P}>0,05)$ da variedade RB845257 (14,7\%, FDN), ambas de ciclo de produção intermediário. Os resultados referentes ao teor de lignina (Lig, \%FDN), apresentados na Tabela 2, mostram-se decrescentes, com o aumento da idade de colheita, ocorrendo o inverso na proporção de Brix e Pol e no teor de matéria seca das variedades de cana-de-açúcar. A lignina é o fator primário que pode limitar o potencial de digestão dos carboidratos fibrosos onde está quimicamente ligada (Van Soest, 1994), pois é de baixa ou nula digestibilidade (Marais, 2000). A limitação da digestão deve-se à função física da lignina como substância que favorece a rigidez parietal, bem como às características de suas ligações químicas com os polissacarídeos estruturais, também conhecida como fração lignocelulósica, à inibição da atividade enzimática ou mesmo à inter-relação de todos estes fatores (Ferreira, 1994).

Como alimento exclusivo para ruminantes, a canade-açúcar tem baixo valor nutricional, por ser um alimento desbalanceado em termos de nutrientes tanto para os ruminantes, como para os microrganismos ruminais. Entre as três variedades de cana-deaçúcar em estudo, aquelas de ciclo de produção intermediário foram qualitativamente superiores e, entre estas, a variedade SP79-1011 foi melhor, pois destacou-se nos maiores $(\mathrm{P}<0,05)$ valores de Brix e Pol e nos menores $(\mathrm{P}<0,05)$ valores da relação FDN/Pol e Lig.

\section{Fracionamento dos carboidratos}

As proporções de cada fração de carboidratos, nas três variedades de cana-de-açúcar estudadas, podem ser observadas na Tabela 3.

Percebe-se que houve diferença $(\mathrm{P}<0,05)$, pelo teste Duncan, apenas para a fração $\mathrm{B}_{2}$ (fração potencialmente degradável dos carboidratos fibrosos) entre as três variedades em estudo. Isto poderia ser devido ao fato de que as variedades de ciclo de produção intermediário SP79-1011 e RB845257 $\left(B_{2}=33,3\right.$ e $\left.30,3 \%\right)$ poderão fornecerem mais energia para os microrganismos que fermentam os carboidratos fibrosos (CF) e carboidratos não-fibrosos (CNF), se esta fração $\left(B_{2}\right)$ tiver tempo suficiente

Tabela 3 - Frações de carboidratos de variedades de cana-de-açúcar (\% dos carboidratos totais)

Table 3 - Carbohydrates fractions of sugarcane varieties (\% of the total carbohydrates)

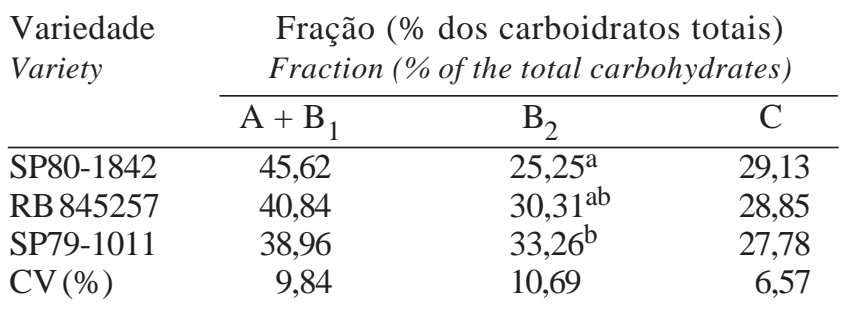

$A+B_{1}=100-\left(B_{2}+C\right) \cdot A+B_{1}-$ carboidratos solúveis em detergente neutro ( $A+B_{1}-$ neutral detergent soluble carbohydrates); $\mathrm{B}_{2}$ - carboidrato fibroso disponível ( $B_{2}$ - available fiber carbohydrates); $C$ - fibra indigestível ( $C$ - indigestible fiber).

$\mathrm{Na}$ coluna, médias seguidas de letras diferentes diferem $(P<0,05)$ pelo teste Duncan (Mean within a column followed by different letters differ $[P<.05]$ by Duncan test). 
para ser degradada totalmente, quando comparada à variedade de ciclo precoce SP80-1842 ( $\left.\mathrm{B}_{2}=25,3 \%\right)$, o que poderia aumentar na eficiência de síntese de proteína microbiana. Cabral et al. (2000) e Pereira et al. (2000) encontraram valores distintos de 21,5 e $41,3 \%$ dos carboidratos, respectivamente, para a fração $B_{2}$, sem informar qual variedade foi utilizada.

Não houve diferença $(\mathrm{P}>0,05)$ entre as variedades estudadas nas frações $\mathrm{A}+\mathrm{B} 1$ e $\mathrm{C}$ dos carboidratos. Existem poucos resultados publicados sobre 0 fracionamento dos carboidratos para cana-de-açúcar e os encontrados por Cabral et al. (2000) e Pereira et al. (2000). Apesar de serem iguais quanto aos valores de $A+B_{1}(36 \%)$, estes resultados divergiram quanto aos valores observados para a fração $\mathrm{C}$, que foram, respectivamente, de 42,5 e 22,7\% mostrando a necessidade de padronização nos métodos de análise, bem como melhor caracterização das variedades de cana-de-açúcar utilizadas.
Cinética de degradação dos carboidratos fibrosos e não-fibrosos e da matéria seca

As médias das estimativas para as variáveis da cinética de degradação in vitro dos carboidratos, pelas técnicas gravimétrica e de produção de gás, de três variedades de cana-de-açúcar, estão relacionadas na Tabela 4.

Pode ser observado na Tabela 4 que as variedades em estudo apresentaram diferenças $(\mathrm{P}<0,05)$ para tempo de latência (L), no método in vitro pela técnica gravimétrica. Os valores observados foram, respectivamente, 9,3; 8,1; e 7,9 horas para as variedades SP80-1842, RB845257 e SP79-1011, sendo que a variedade SP79-1011 foi melhor que as outras duas variedades; além da menor quantidade de lignina (12,2\%, FDN) apresentada Van Soest (1994), verificou-se que a utilização da FDN também pode ser realizada diferentemente pelos microrganismos ruminais e, dessa maneira, a FDN pode possuir

Tabela 4 - Médias das estimativas para as variáveis relativos à cinética de degradação in vitro dos carboidratos, pelas técnicas gravimétrica e de produção de gás de variedades de cana-de-açúcar

Table 4 - Estimate means for the variables related to the in vitro degradation kinetics of the carbohydrates by the gravimetric and gas production techniques of sugarcane varieties

\begin{tabular}{|c|c|c|c|c|}
\hline \multirow[t]{2}{*}{$\begin{array}{l}\text { Característica } \\
\text { Characteristic }\end{array}$} & \multicolumn{3}{|c|}{$\begin{array}{l}\text { Variedade de cana-de-açúcar } \\
\text { Sugarcane variety }\end{array}$} & \multirow[t]{2}{*}{ CV(\%) } \\
\hline & SP80-1842 & RB845257 & SP79-1011 & \\
\hline \multicolumn{5}{|c|}{$\begin{array}{l}\text { Técnica gravimétrica } \\
\text { Gravimetric technique }\end{array}$} \\
\hline $\begin{array}{l}\text { B (\%) } \\
\text { c }\left(h^{-1}\right) \\
L(h) \\
\text { I(\%) }\end{array}$ & $\begin{array}{c}31,2 \\
4,2 \\
9,3^{\mathrm{b}} \\
56,4\end{array}$ & $\begin{array}{c}27,3 \\
4,1 \\
8,1^{\mathrm{b}} \\
61,2\end{array}$ & $\begin{array}{c}34,4 \\
4,0 \\
7,9^{\mathrm{a}} \\
54,5\end{array}$ & $\begin{array}{r}15,4 \\
32,9 \\
23,9 \\
8,9\end{array}$ \\
\hline $\begin{array}{l}\text { DEFDN }(\%) \\
\text { EDNDF (\%) }\end{array}$ & $8,9^{\mathrm{b}}$ & $8,2^{b}$ & $10,3^{\mathrm{a}}$ & 22,6 \\
\hline \multicolumn{5}{|c|}{$\begin{array}{l}\text { Técnica de produção de gás } \\
\text { Gas production technique }\end{array}$} \\
\hline $\begin{array}{l}\mathrm{Vf}_{1}(\mathrm{~mL}) \\
\mathrm{C} 1\left(\mathrm{~h}^{-1}\right) \\
\mathrm{L}(\mathrm{h}) \\
\mathrm{Vf}_{2}(\mathrm{~mL}) \\
\mathrm{C} 2\left(\mathrm{~h}^{-1}\right) \\
\mathrm{R}^{2}\end{array}$ & $\begin{array}{c}5,1^{\mathrm{b}} \\
26,6 \\
3,5 \\
10,8 \\
2,7 \\
0,99\end{array}$ & $\begin{array}{c}5,6^{\mathrm{ab}} \\
29,6 \\
3,5 \\
11,3 \\
2,6 \\
0,99\end{array}$ & $\begin{array}{c}7,3^{\mathrm{a}} \\
31,1 \\
3,4 \\
11,4 \\
2,7 \\
0,97\end{array}$ & $\begin{array}{r}10,1 \\
6,8 \\
4,3 \\
5,6 \\
4,5\end{array}$ \\
\hline
\end{tabular}

B - fração potencialmente degradável (B - potentially degradable fraction); $\mathrm{c}$ - taxa de degradação da fração $\mathrm{B}$ (degradation rate of the $B$ fraction); $L$ - tempo de latência ( $L$ - lag time); I - fração indegradável da fibra em detergente neutro (FDN) (I - undegradable fraction of neutral detergent fiber (NDF)); DEFDN - degradabilidade efetiva da FDN ( EDNDF - effective degradation of the NDF).

$\mathrm{Vf}_{1}$ - volume máximo de gás da fração de CNF ( $V f_{1}$ maximum gas volume of the NFC fraction); C1 - taxa de digestão para a fração de CNF (C1 - digestion rate of NFC fraction); $\mathrm{L}$ - latência ( $L$ - lag time); $\mathrm{Vf}_{2}$ - volume máximo de gás da fração de $\mathrm{CF}\left(\mathrm{Vf}_{2}-\right.$ maximum gas volume of the FC fraction); $C 2$ - taxa de digestão para a fração de CF (C2 - digestion rate for FC fraction).

Médias, na linha, seguidas por letras diferentes são diferentes pelo teste Duncan $(P<0,05)($ Means, within row, followed by different letters are different by Duncan test $(P<.05)$. 
frações de fácil e difícil digestão microbiana. Santos (1994), estudando a degradabilidade da cana-deaçúcar pelo método in situ, observou tempo de latência de 4 horas. Este valor foi bem próximo dos observados pela técnica de produção de gás apresentada na Tabela 4, a qual, porém, não mostrou diferença.

A variedade SP79-1011 apresentou diferença $(\mathrm{P}<0,05)$, pelo teste Duncan, para os resultados estimados da degradabilidade efetiva da FDN (DEFDN $=10,3 \%)$, sendo fator principal para esta superioridade a fração potencialmente degradável da FDN, pois esta foi, respectivamente, 10,3 e $26,3 \%$ maior que as variedades SP80-1842 e RB845257 (Tabela 3). Santos (1994), trabalhando com degradabilidade in situ da cana-de-açúcar com 63,2\% de FDN na MS em vacas das raças Holandesas e Jersey, observou valores de 25,1 e 16,1\%, respectivamente. Franzolin \& Franzolin (2000) obtiveram DEFDN de 31,4\%, com taxa de passagem de $5 \mathrm{~h}^{-1}$, realizada, também, pela mesma técnica. Apesar de os resultados encontrados neste estudo para estimativa da DEFDN serem consideravelmente inferiores aos verificados por Santos (1994) e Franzolin \& Franzolin (2000), os quais não levaram em consideração o período de latência.

Os dados de taxa de degradação apresentados pela técnica gravimétrica revelaram menor precisão, pois tiveram coeficiente de determinação $\left(\mathrm{R}^{2}\right.$ médio $=0,90)$ e coeficiente de variação $(\mathrm{CV}=32,9 \%)$ piores que os apresentados pela técnica de produção de gás $\left(\mathrm{R}^{2}\right.$ médio $=0,99$ e $\left.\mathrm{CV}=4,5 \%\right)$, que apresentaram taxas bem próximas às encontradas na literatura para cana-de-açúcar, as quais variavam entre 1,8 e 3,9 h-1 (Santos, 1994; Cabral et al., 2000; Pereira et al., 2000; Franzolin \& Franzolin, 2000; Campos et al., 2001).

As curvas de produção de gás da MS, dos CF e CNF estão representadas na Figura 1. No método de produção de gás, houve diferença $(\mathrm{P}<0,05)$, pelo teste Duncan, para o volume final de gases produzidos pelos CNF. Nas primeiras horas de incubação, quase $100 \%$ dos gases produzidos no sistema corresponderam aos CNF, sendo a principal fonte de energia para o crescimento microbiano (Figura 1), com superioridade da variedade SP79-1011, seguida pela RB845257 e SP80-1842, respectivamente.

Os gases gerados pelos CNF representaram, em média, 32,0; 33,1; e 39,0\% para as variedades SP80-1842, RB845257 e SP79-1011, respectivamente. As variedades de ciclo de produção intermediário
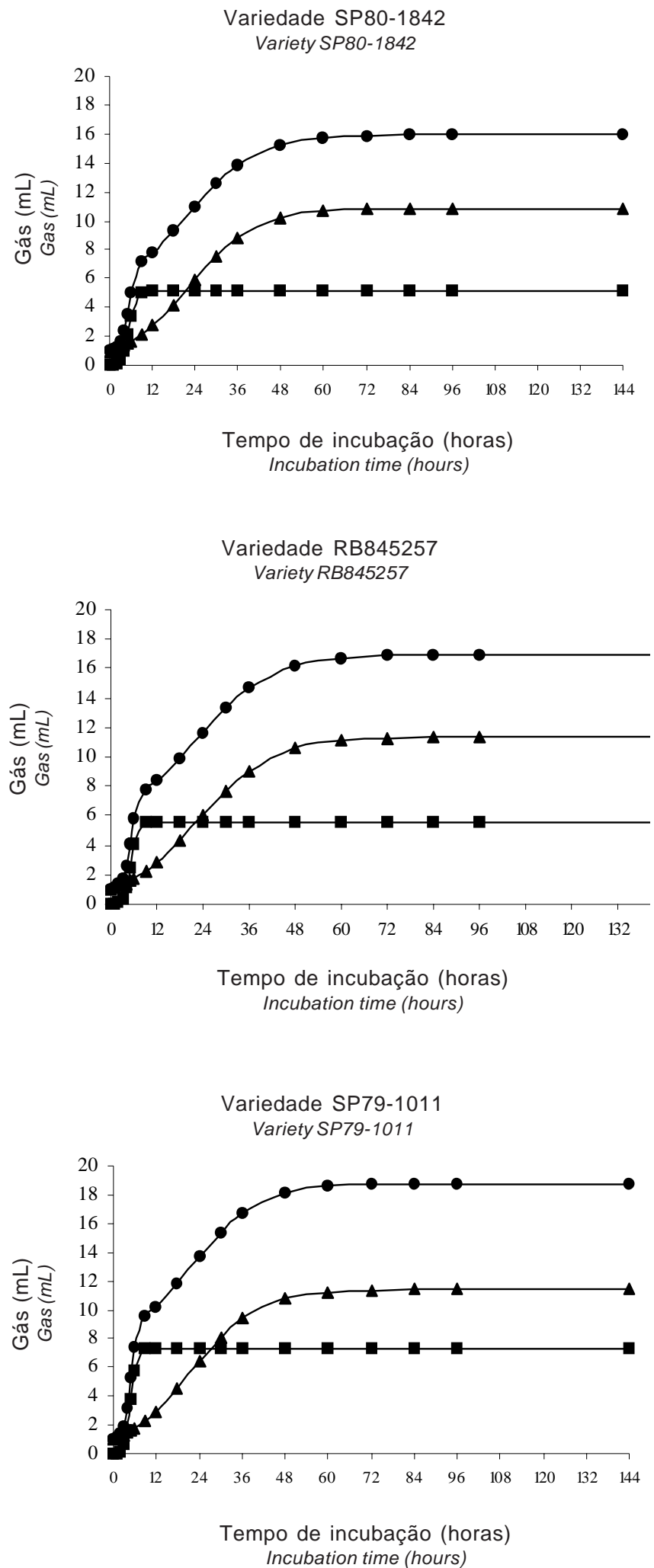

Figura 1 - Curvas de produção de gás da matéria seca (MS), carboidratos não-fibrosos (CNF) e carboidratos fibrosos (CF) das variedades de cana-de-açúcar.

Figure 1 - Gas production curves of dry matter (DM), no- fiber carbohydrates (NFC) and fibrous carbohydrates (FC) of sugarcane varieties. 
SP79-1011 e RB845257 foram as que produziram maior volume final de gases produzidos pelos CNF (Vf1), o que pode estar relacionado ao maior valor de Brix (\% caldo), Pol (\% cana) e à menor concentração de lignina (\%, FDN). A menor concentração de lignina, nestas variedades, facilitaria o acesso dos microrganismos aos $\mathrm{CF}$, comprovado pela maior fração potencialmente degradável (parâmetro B) pelo método gravimétrico.

Quando a assíntota dos CNF foi estabelecida, parece ter existido um segundo período de latência, com menor intensidade, logo após o tempo de 12 horas de incubação, para todas as variedades de cana-de-açúcar em estudo, apresentando curva de comportamento diáuxico. Este tipo de comportamento da curva de crescimento microbiano é muito comum, quando há presença de nutrientes no meio que competem pelo mesmo sistema de transporte, como no caso dos açúcares regulados pelo sistema "PEPPTS"(Moat \& Foster, 1997), ou quando da presença de nutrientes de natureza muito heterogênea.

\section{Conclusões}

A variedade SP79-1011 foi a que apresentou melhores características produtivas, composição químico-bromatológica, além de melhores valores das variáveis de cinética de degradação dos carboidratos fibrosos (CF) e não-fibrosos (CNF).

Existiram variações para as características produtivas e de composição química-bromatológica, no teor de Brix, Pol e lignina entre as variedades de cana-de-açúcar analisadas. Para o fracionamento de carboidratos e as variáveis de cinética da degradação dos CF, CNF e da MS existiram variações no teor da fração $B_{2}$, no tempo de latência, na degradabilidade efetiva da FDN e no volume final de gás entre as variedades de cana-de-açúcar analisadas.

A técnica de produção de gás apresentou resultados mais confiáveis, com maior coeficiente de determinação $\left(\mathrm{R}^{2}\right)$ e menor coeficiente de variação $(\mathrm{CV})$, quando comparada à técnica gravimétrica.

\section{Literatura Citada}

ALVAREZ, F. J.; PRESTON, T.R. Performance of fattening cattle on immature or mature sugar cane. Tropical Animal Production, v.1, n.2, p.106-111, 1976.

ASSOCIATION OF OFFICIAL ANALYTICAL CHEMISTS AOAC. 1990. Official methods of analysis. 15.ed., Arlington, Virginia. 1117p.
BANDA, M.; VALDEZ, R.E. Effect of stage of maturity on nutritive value of sugar cane. Tropical Animal Production, v.1, n.1, p.94-97, 1976.

BRIEGER, F.O. Início da safra. Como determinar a maturação. Boletim Informativo Copereste, v.4, p.1-3, 1968.

BRUGNARO, C.; HEISE, C.E.; PERES, F.C. et al. Maximização da produção de uma usina de açúcar. Brasil Açúcareiro, v.106, n.5 e 6, p.2-8, 1988.

CABRAL, L.S; VALADARES FILHO, S.C.; MALAFAIA, P.A.M. et al. Frações de carboidratos de alimentos volumosos e suas taxas de degradação estimadas pela técnica de produção de gases. Revista Brasileira de Zootecnia, v.29, n.6, p.2087-2098, 2000. (Suplemento 1)

CAMPOS, F.P.; SAMPAIO, A.A.M.; VIEIRA, P.F. et al. Digestibilidade in vitro/ gás de volumoso exclusivos ou combinados avaliados pelo resíduo remanescente da digestão da matéria seca e produção de gás. Revista Brasileira de Zootecnia, v.30, n.5, p.1579-1589, 2001.

CARVALHO, G.J. Avaliação do potencial forrageiro e industrial de variedades de cana-de-açúcar (ciclo de ano) em diferentes épocas de corte. Lavras: Escola Superior de Agricultura de Lavras, 1992. 75p. Dissertação (Mestrado em Agronomia) - Escola Superior de Agricultura de Lavras, 1992.

COELHO, M.B.; RIBEIRO, S.N.N. Análise dos dados meteorológicos do Município de Ponte Nova - MG. Brasil Açucareiro, v.106, n.4, p.26-36, 1988.

FERREIRA, W.M. Os componentes da parede celular vegetal na nutrição de não-ruminantes. In: SIMPÓSIO INTERNACIONAL DE PRODUÇÃO DE NÃO-RUMINANTES, 1994. REUNIÃO ANUAL DA SOCIEDADE BRASILEIRA DE ZOOTECNIA, 31., 1994, Maringá. Anais... Maringá: Sociedade Brasileira de Zootecnia,1994. p.85-8113.

FRANZOLIN, R.; FRANZOLIN, M.H.T. População protozoários ciliados e degradabilidade ruminal em búfalos e bovinos zebuínos sob dieta à base de cana-de-açúcar. Revista Brasileira de Zootecnia, v.29, n.6, p.1853-1861, 2000.

GONÇALVES, L.A.C. Influência da fibra e da Pol da cana e da pureza do caldo no processo de fabricação de açúcar e álcool. Brasil Açucareiro, v.105, n.4, 5 e 6, p.49-64, 1987.

GOODING, E.G.B. Effect of quality of cane on its value as livestock feed. Tropical Animal Production, v.7, n.1, p.72-91, 1982.

LOVADINI, L.A.C. Efeito da maturidade da planta sobre a composição em fibra bruta, celulose, lignina e digestibilidade da celulose in vitro, em variedades de cana-de-açúcar. Piracicaba: Escola Superior de Agricultura “Luiz de Queiroz”, 1971. 67p. Dissertação (Mestrado) Escola Superior de Agricultura "Luiz de Queiroz”, 1971.

MARAIS, J.P. Use of markers. In: D’MELLO, J.P.F. (Ed.) Farm animal metabolism and nutrition: critical reviews. Wallingford: CAB International, 2000. p.255-277.

McDONALD, E.I. A revised model for the estimation of protein degradability in the rumen. Journal Agricultural Science, v.96, n.1, p.251-252, 1981.

MENKE, K.H.; RAAB, L.; SALEWSKI, A. et al. The estimation of the digestibility and metabolizable energy contain of ruminant feedstuffs from the gas production when they are incubated with rumen liquor in vitro. Journal Agricultural Science, v.93, p. 217-223, 1979.

MERTENS, D.R. Analysis of fiber in feeds and its uses in feed evaluation and ration formulation. In: SIMPÓSIO INTERNACIONAL DE RUMINANTES. REUNIÃO ANUAL DA SOCIEDADE BRASILEIRA DE 
ZOOTECNIA, 29., 1992, Lavras. Anais... Lavras: Sociedade Brasileira de Zootecnia, 1992. p.1-32.

MERTENS, D.R. Dietary fiber components: relationship to the rate and extent of ruminal digestion. Federation Proceedings, v.36, n.2, p.487-192, 1977.

MERTENS, D.R.; LOFTEN, J.R. The effect of starch on forage fiber digestion in vitro. Journal of Dairy Science, v.63, n.9, p.1437-1446, 1980.

MERTENS, D.R. Rate and extent of digestion. In: FORBES, J.M.; FRANCE, J. (Eds.) Quantitative aspects of ruminant digestion and metabolism. Cambridge: $C A B$ International, Cambridge University Press, 1993. p.13-51.

MOAT, A.G.; FOSTER, J. W. Microbial physiology. 1.ed. New York, 1997. 580p.

ORSKOV, E.R. Evaluation of fibrous diets for ruminants. In: INTERNATIONAL SEMINAR ON FEEDINGS EVALUATION MODERN ASPECTS-PROBLEMSFUTURE TRENDS, 1986, Aberdeen. Procedings... Aberdeen: Rowett Research Institute, 1986. 38-41.

PEIXOTO, A.M. A cana-de-açúcar como recurso forrageiro. In: CONGRESSO BRASILEIRO DE PASTAGEM $\mathrm{e}$ SIMPÓSIO SOBRE MANEJO DE PASTAGENS, 8., 1986, Piracicaba. Anais... Piracicaba: Fundação de Estudos Agrários Luiz de Queiroz, 1986. p.17-47.

PELL, A.N.; SCHOFIELD, P. Computerized monitoring of gas production to measure forage digestion in vitro. Journal of Dairy Science, v.76, n.9, p.1063-1073, 1993.

PEREIRA, E.S.; QUEIROZ, A.C.; PAULINO, M.F. et al. Determinação das frações protéicas e de carboidratos e taxas de degradação in vitro da cana-de-açúcar, da cama de frango e do farelo de algodão. Revista Brasileira de Zootecnia, v.29, n.6, p.1887-1893, 2000.

PEREIRA, J.C. Degradación ruminal de diversos subproductos agroindustriales. Madrid: Universidad Politécnica de Madrid, 1992. 223p. Doutorado - Universidad Politécnica de Madrid, 1992.

RODRIGUES, A.A.; CRUZ, G.M.; BATISTA, L.A.R. et al. Qualidade de dezoito variedades de cana-de-açúcar como alimento para bovinos. In: REUNIÃO ANUAL DA SOCIEDADE BRASILEIRA DE ZOOTECNIA, 38., 2001, Piracicaba. Anais... São Paulo: Sociedade Brasileira de Zootecnia/ Sonopress, [2001]. CD-ROM. Nutrição de Ruminantes.

RODRIGUES, A. A.; ESTEVES, S.N. Cana-de-açúcar e uréia para alimentação de bovinos na época da seca. São Carlos: Embrapa-UEPAE, 1992. 30p. (Circular Técnica, 6)
SANTOS, R. M. Cinética da digestão ruminal de alguns alimentos concentrados e volumosos para vacas das raças holandesa e jersey. Lavras: Escola Superior de Agricultura de Lavras, 1994. 56p. Dissertação (Mestrado em Zootecnia) - Escola Superior de Agricultura de Lavras, 1994.

SCHOFIELD, P.; PITT, R.E.; PELL, A.N. Kinetic of fiber digestion from in vitro gas production. Journal of Animal Science, v.72, n.11, p.2980-2991, 1994.

SNIFFEN, C.J.; O’CONNOR, J.D.; VAN SOEST, P.J. et al. A net carbohydrate and protein system for evaluating cattle diets. II. Carbohydrate and protein availability. Journal of Animal Science, v.70, n.7, p.3562-3577, 1992.

THEODOROU, M.K.; WILLIAMS, B.A.; DHANOA, M.S. et al. A simple gas production method using a pressure transducer to determine the fermentation kinetics of ruminant feeds. Animal Feed Science and Technology, v.48, p.185197, 1994.

THIAGO, L.R.L.S.; GILL, M. Consumo voluntário: fatores relacionados com a degradação e passagem da forragem pelo rúmen. Campo Grande: Embrapa - CNPGC, 1993.1. reimp. 65p. (Documentos, 43)

UNIVERSIDADE FEDERAL DE VIÇOSA - UFV. SAEG Sistema de análise estatística e genética. Versão 8.0. Viçosa, MG. 2000.

VALADARES FILHO, S.C.; ROCHA Jr., V.R.; CAPPELLE, E.R. Tabelas brasileiras de composição de alimentos para bovinos. Viçosa, MG: Universidade Federal de Viçosa, 2002. 297p.

Van SOEST, P.J. Nutritional ecology of the ruminant. 2. ed. London: Comstock Publishing Associates - Cornell University Press, 1994. 476p.

Van SOEST, P.J.; ROBERTSON, J.B.; LEWIS, B.A. Methods for dietary fiber, neutral detergent fiber, and nonstarch polyssacarides in relation to animal nutrition. Journal of Dairy Science, v.74, n.10, p.3583-3597, 1991.

WALDO, D.R. Factors influencing voluntary intake of forage. In: NATIONAL CONFERENCE ON FORAGE QUALITY EVALUATION AND UTILIZATION, 1970, Lincoln, Nebraska. Proceedings ... Lincoln: Nebraska Center for Continuing Education, 1970. p.1-22.

WEISS, W.P. Method estimates available energy value for ruminants. Feedstuffs, p.13-14, 1993. 